\title{
Non-intentional asphyxiation deaths due to upper airway interference in children 0 to 14 years
}

\author{
Anne Altmann, Terry Nolan
}

\begin{abstract}
Objective-This study was undertaken to identify avoidable, contributing factors associated with non-intentional asphyxiation deaths due to upper airway interference in children 0 to 14 years.
\end{abstract}

Design-Historical population based incidence study.

Methods-All postneonatal and childhood deaths by asphyxiation from 1985 to 1994, using appropriate ICD-9-CM codes, were compiled from the Victorian government legislated paediatric mortality surveillance system. Recent cases were identified from the State Coroner's Office. Case definition included children under 15 years who died from upper airway interference such as facial occlusion, head and neck entrapment, rope or cord strangulation, or foreign body.

Results-Of the identified 42 deaths, eight ( $19 \%)$ were caused by a foreign body in the airway, five $(12 \%)$ were due to facial occlusion, $16(38 \%)$ were due to ropes and similar material (seven were homemade rope swings), and $13(31 \%)$ were caused by entrapment (seven were in cots or beds). The average annual rate for asphyxiation deaths by all causes for children 0 to 14 years was $4 \cdot 7$ million. Infants under 1 year had a rate of $20 \cdot 1 /$ million, while the rate for 10 to 14 year olds dropped to $2 \cdot 0$ / million.

Conclusion-Rope swings and rope material are inherently dangerous and frequently prove fatal, especially for older children. For infants, environmental factors are important; in particular food and bedding. Prevention strategies need to be developed that include obligatory standards for the design and manufacture of products for children, appropriate labelling and warnings, and education for children, their carers, and health care professionals.

(Injury Prevention 1995; 1: 76-80)

Keywords: asphyxia, suffocation, mortality, epidemiology.

Accidents, or non-intentional injury, are a major cause of paediatric mortality and premature years of life lost. In 1992, in Victoria, Australia there were 69 non-intentional injury deaths in a total of 308 postneonatal infant and childhood deaths (29 days to 14 years). In the main categories of death, injuries ranked fourth after birth related deaths (94), acquired disease (75), and cot deaths (70), although injuries were the leading cause of death after 1 year. Of the injury deaths there were 32 due to motor vehicles, 16 drownings, 11 fire related, two train accidents, and five $(7 \cdot 2 \%)$, due to accidental asphyxiation. ${ }^{1}$

In Australia in 1992 there were 380 deaths due to non-intentional injury in the 0 to 14 year age group. ${ }^{2}$ Of these $11(2.9 \%)$ and four $(1.0 \%)$ were due to asphyxiation by food and other objects respectively, and $14(3.7 \%)$ were due to suffocation, giving a total of $7 \cdot 6 \%$ due to these types of asphyxiation. ${ }^{2}$

During routine prospective statewide surveillance of injury related deaths in Victorian children a cluster of rope related asphyxiations was noted. As a result it was decided to review all such and similar asphyxiation deaths in children over the 9.5 years that the surveillance system has been active.

Although non-intentional asphyxiation is a relatively rare cause of death, there have been 47 fatalities in children from this cause in the last 9.5 years in Victoria. In this study only the asphyxiation deaths due to upper airway interference were included. These were divided into four mechanism groups as follows: facial occlusion, entrapment of the neck, strangulation from any type of rope material or clothing, and foreign body aspiration. Deaths from involvement of the lower airway were excluded, such as chest compression or drowning. Although many of these 'accidents' may appear to be random mishaps, closer inspection reveals several consistent mechanisms and predictable outcomes.

\section{Subjects and methods}

Since 1985, a statewide government legislated paediatric mortality surveillance system has existed in Victoria, Australia under the auspices of the Consultative Council on Obstetric and Paediatric Mortality and Morbidity. The council is notified of every death in the state under the age of 15 years directly from the Victorian registry of births, deaths, and marriages. The council compiles confidential case histories from a variety of sources which are then reviewed by specialist committees so that any potentially avoidable factors can be identified. 
The council's records on accidental postneonatal infancy and child deaths (29 days to 14 years) were searched. All deaths by asphyxiation from 1985 to June 1994 were drawn using the International Classification of Diseases, 9 th revision, clinical modification (ICD-9-CM). The codes used were: 994.7 -suffocation by bedclothes, cave in, constriction, mechanical, plastic, pressure, and strangulation; 933934-foreign body in pharynx, larynx, trachea, bronchus, and lung; E911-912 - inhalation or ingestion of food or other object causing obstruction of the respiratory tract or suffocation; and E913-accidental mechanical suffocation: in bed/cradle, by plastic bag, by falling earth or other substance, by accidental hanging, due to lack of air (in closed space), or by unspecified means.

The Coroner's Act 1985 in Victoria states that certain deaths must be reported. These include those that were unexpected, unnatural, or violent, that resulted from an accident or injury; that occurred during an anaesthetic; or where a person was held in care. Cases occurring in 1993 and the first half of 1994 were also searched for on the State Coroner's Office's computer system by age and cause of death.

All the cases were verified using information in the files on the investigations undertaken by the state coroner. The information reviewed for each case included: age, date of death, circumstances of the death, results of postmortem examination if carried out, and identification, if possible, of any avoidable factors.

All cases due to lower airway interference were excluded. This included five asphyxial deaths caused by crushing or burying. Other asphyxial deaths excluded were those due to aspiration of vomit, drowning, fires, associated with motor vehicle accidents, suicides, homicides, and sudden infant death syndrome (SIDS). SIDS is classified by a combination of a centralised postmortem examination and a death scene investigation. These deaths are not classified as asphyxiation unless there is unequivocal evidence of such from the investigations.

The asphyxial deaths were divided into groups according to the anatomic level of upper airway involvement. The groups were: facial occlusion; entrapment of head of neck; rope or cord strangulation; and airway obstruction due to a foreign body (food or other object).

\section{STATISTICAL ANALYSIS}

Data on the Victorian population figures was obtained from the Australian Bureau of Statistics estimated resident population by sex and age from 1985 to 1993. Death rates were calculated by dividing the number of deaths observed by the number of children in the age group at risk. Because the annual number of deaths in each subgroup of asphyxiation was small, average annual rates were derived for the total study period ( $9 \cdot 5$ years).

\section{Results}

From 1985 to June 1994 there were 47 deaths due to non-intentional asphyxiation. Five due to crushing or burying were excluded. The remaining 42 deaths are tabulated by the mechanism causing death (table 1 ).

Of the 42 deaths, eight ( $19 \%$ ) were caused by a foreign body in the airway, six of which were due to food and two due to objects. Five $(12 \%)$ were caused by facial occlusion, one of which involved plastic material.

Of the 29 strangulation deaths, $16(38 \%)$ were due to ropes, cords, and other such material, and $13(31 \%)$ were due to head or neck entrapment. Seven of the 13 deaths by entrapment were caused by cots or beds, seven of the 16 rope or cord associated deaths were due to homemade rope swings, and three were due to blind or curtain cords.

There were 12 deaths in infants under the age of 1 year. Of the four due to facial occlusion, two were related to couches and one involved plastic material. Another four became entrapped, two in the cot and one whose cardigan caught on the cot. One infant strangled on a rattle cord suspended over the cot and three inhaled a foreign body. Half were associated with an unsafe sleeping environment, for example, an inadequately sized mattress, inappropriate type of bed for the child's age, or objects attached to the cot.

The average annual rate for asphyxiation deaths by all causes in children 0 to 14 years was $4 \cdot 7 /$ million (table 2). However, the age group most at risk is that of infants under 1 year with a rate of $20 \cdot 1 /$ million/year. The rates then drop off with increasing age to a rate of $2.0 /$ million year for the 10 to 14 year olds. In the infants, all mechanisms feature prominently except strangulation by ropes. In contrast, ropes are the most common cause of asphyxial death for children over 1 year of age.

\section{Discussion}

The results indicate two main risk groups for asphyxiation: infants, who were at risk from facial occlusion, neck entrapment, and foreign body aspiration and children over 1 year who were at risk from strangulation by ropes. The main mechanisms of asphyxiation are noticeably consistent and repetitive, and virtually all these deaths could have been prevented.

The excellent surveillance system in place in Victoria for paediatric mortality made it possible to identify the entire defined population in the selected time period. Although a preceding primary cause is not annotated on the death certificate (for example asphyxiation with anoxia resulting in cerebral palsy with death at a later date), misclassification would be unlikely due to statutory investigations undertaken on all paediatric deaths by the council. The coroner's records provided much additional information on intent and circumstances. After reviewing available evidence there were no indications to suspect suicide, for example, depression or prior disputes - in any of our cases. Due to the conservative classification of SIDS, and exclusion of these cases from the study, some underestimation of the true incidence of asphyxiation may have resulted.

The rate for asphyxiation deaths in Victoria over the study period, excluding deaths due to 
Table 1 Non-intentional asphyxiation deaths in children 0 to 14 years, by mechanism of asphyxiation

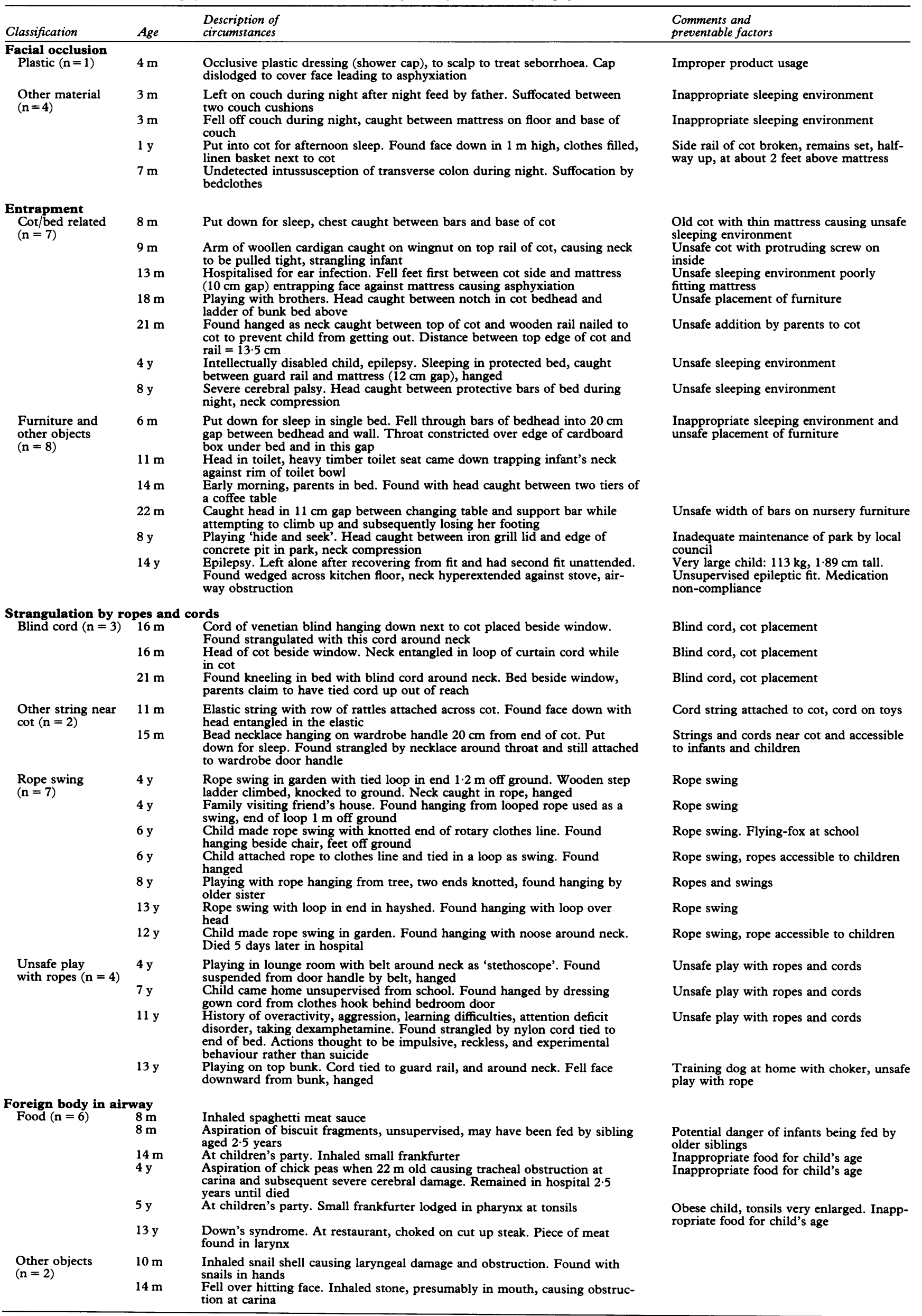


Table 2 Total No (\%) and average annual rate ${ }^{\star}$ of asphyxiation deaths by cause and age group in children 0 to 14 years in Victoria, Australia, 1985-Fune 1994

\begin{tabular}{|c|c|c|c|c|c|c|c|c|c|c|}
\hline \multirow[b]{2}{*}{ Mechanism } & \multicolumn{2}{|c|}{$0-14$ years } & \multicolumn{2}{|c|}{$<1$ year } & \multicolumn{2}{|c|}{$1-4$ years } & \multicolumn{2}{|c|}{ 5-9 years } & \multicolumn{2}{|c|}{$10-14$ years } \\
\hline & No $(\%)$ & Rate & No & Rate & No & Rate & No & Rate & No & Rate \\
\hline $\begin{array}{l}\text { Facial occlusion } \\
\text { Entrapment } \\
\text { Ropes } \\
\text { Foreign body }\end{array}$ & $\begin{array}{r}5(12) \\
13(31) \\
16(38) \\
8(19)\end{array}$ & $\begin{array}{l}1.7 \dagger \\
1.5 \\
1.8 \\
0.9\end{array}$ & $\begin{array}{l}4 \\
4 \\
1 \\
3\end{array}$ & $\begin{array}{l}6 \cdot 7 \\
6 \cdot 7 \\
1 \cdot 7 \\
5 \cdot 0\end{array}$ & $\begin{array}{l}1 \\
6 \\
7 \\
3\end{array}$ & $\begin{array}{l}0.4 \\
2 \cdot 5 \\
3 \cdot 0 \\
1 \cdot 3\end{array}$ & $\begin{array}{l}0 \\
2 \\
4 \\
1\end{array}$ & $\begin{array}{l}\overline{0} \\
1 \cdot 4 \\
0 \cdot 3\end{array}$ & $\begin{array}{l}0 \\
1 \\
4 \\
1\end{array}$ & $\begin{array}{l}\overline{0.3} \\
1.3 \\
0.3\end{array}$ \\
\hline All causes & $42(100)$ & $4 \cdot 7$ & 12 & $20 \cdot 1$ & 17 & $7 \cdot 2$ & 7 & $2 \cdot 4$ & 6 & $2 \cdot 0$ \\
\hline
\end{tabular}

*Average annual death rate/ $1000000 /$ year. + Rate for 0-4 years.

foreign body inhalation was $3 \cdot 8 / \mathrm{million} /$ year, with the Australian rate for suffocation, in 1992, comparable at $3 \cdot 7 /$ million/year. ${ }^{2}$ A national analysis of childhood injury deaths in the USA, over a five year period, 1980-5, reported higher rates for childhood suffocation $-7 /$ million/year population of children 0 to 14 years. ${ }^{3}$

A total of 17 deaths $(40 \%)$ related to the child's own bed or bed furnishings, an inappropriate sleeping place for the child's age, or to furniture, cords, or other articles within close proximity of the cot. Despite the publicity and the design standards regarding infant cots, deaths continue to occur in this environment. The importance of using a cot with the appropriate design standards needs to be emphasised, along with using an appropriately fitting mattress. Design standards must also apply to special beds for the disabled.

The risk of death as a direct result of the sleeping environment, and in particular the infant cot, has been stressed by numerous authors. ${ }^{4-10}$ Regulations regarding infant cribs were first set in the USA in 1974, and reports since then have varied as to whether there has been a reduction in the number of associated crib deaths. Feldman and Simms quote a US Consumer Product Safety Commission (USCPSC) report claiming that there was approximately a $50 \%$ reduction in the number of crib strangulations since the introduction of legislation. ${ }^{8}$ In contrast Kraus, after reviewing deaths in Californian children due to suffocation and strangulation from 1960 to 1981 , found no evidence of a statistically significant decline. ${ }^{4}$ These differing findings may well be due to a lag time in discarding of old cribs after introduction of regulations.

Cots and beds should be placed firmly against the wall, and proximity to blind cords and other potentially dangerous articles avoided. Restraining devices fitted to the bed or cot are hazardous, as illustrated by one death that was a direct consequence of a bar over the cot. Although Australian standards on cots make provision against any protrusion into the cot, injuries are still likely to arise from broken or repaired cots that are outside the set safety standards. The death of a child in our series due to a cardigan catching on a wingnut in the cot was not an isolated incident. ${ }^{11}$ These dangers of restraining devices, protrusions, and repairs were emphasised by Bergeson et al 18 years ago. 6

A couch is not a safe sleeping environment for infants because of its inability to prevent facial smothering due to poor head control. There were no deaths in our series associated with waterbeds, sheepskin rugs, or polystyrene bead filled cushions, each of which have been noted to pose a risk to infants. ${ }^{9}$ The importance of age appropriate bedding cannot be overemphasised.

The largest cause of death in our series was strangulation due to ropes and cords, in children aged 11 months to 13 years, the majority of whom were male. For infants who are not mobile, the risk of strangulation was from cords on objects, both within and outside the cot for example, strings attached to toys, harnesses, and clothing that can pull tight around the neck. The danger of infant strangulation due to cords has been raised in several case reports and the avoidance of these is strictly advised. ${ }^{611}$

Three toddlers were strangled by blind or curtain cords, and one by a necklace left hanging beside the cot. Two recent fatal case reports highlight these dangers - the first of a toddler by a corded light switch specifically designed for use by children, ${ }^{12}$ and the second by a loose lamp flex during the night. ${ }^{13}$ Toddlers become increasingly mobile, lack a sense of danger, and are curious by nature and therefore are at risk from a variety of objects around the house and near the cot.

There were 11 deaths in children 3 years and over attributable to rope, belts, or cords. Play with ropes is inherently dangerous even if the child is thought old enough to be careful, as illustrated by the death of four children aged 11 to 13 years. Seven deaths were due to homemade rope swings of varying types, usually made with a loop at the end or with the two ends tied together. The risk of childhood strangulation due to unsafe play with such ropes must be stressed. ${ }^{811}$

In Australia in 1992 the rate for nonintentional death due to asphyxiation by food was $2.9 / \mathrm{million} /$ year, and by other objects was $1 \cdot 1 /$ million/year in children 0 to 14 years. ${ }^{2}$ The Victorian average annual rate was less, at 0.9 / million/year for foreign body aspiration, food, and other objects together. USA national rates for aspiration of food and other material were 4 and $3 /$ million/year respectively, ${ }^{3}$ similar to the Australian rates.

Six of the eight deaths due to foreign body inhalation were in children under the age of 5 years. Factors such as a younger age group, a more intense atmosphere, playing, laughing or shouting while eating, and lack of supervision during meals, may increase the risk of choking. These elements are likely to occur in the day care setting, ${ }^{14}$ or at children's parties.

Hotdogs have been cited as a major cause of fatal chokings in children. ${ }^{715} 16$ Two Victorian children died after choking on a party frankfurter. Although not immediately evident as a risky foodstuff, the innocent and well-loved frankfurter is inherently dangerous for small children due to its size, shape, and consistency. ${ }^{16}$ Measures such as age appropriate food, a supervised eating environment, and not allowing young siblings to feed an infant should be adopted, together with promotion of correct responses to aspiration emergencies. 
The prevention of asphyxiation deaths needs tackling from a variety of angles. The failure of voluntary standards emphasises the need for more standards to be legislated. ${ }^{17}$ Australia has many voluntarily adopted standards that cover articles with which children will come into contact. However, legislation only exists regarding the size of toys for children under 3 years where the toy may represent an inhalation or ingestion risk. ${ }^{18}$ In the USA, after a USCPSC review of 126 crib related deaths, ${ }^{19}$ legislation was passed regulating the distance between crib slats and the space between the mattress and side rails. ${ }^{20}$ Currently in Australia standards relating to cots are under review, and legislation is being contemplated.

There are no codes or regulations in Australia that cover the labelling of food regarding its age appropriateness, while these types of labelling requirements on prepackaged food for infants and children were introduced in 1979 in Sweden, ${ }^{21}$ and are also seen in other European countries. Labelling and warnings on products, in particular children's equipment, and hazardous foodstuffs need to be considered. All domestic market rope products, together with equipment that contains loose rope or cord (for example skipping ropes and clothes lines), should carry product warnings, preferably non-removable. Written warnings need to state the potential hazard, rather than an age below which the product is deemed inappropriate. Product labelling has the ability to reach members of the public not always targeted by preventative campaigns and therefore is an excellent mechanism for information dissemination.

Hazardous products for children are frequently those available and marketed to the general public. Education and anticipatory guidance can address this problem, along with the issue of access to age inappropriate food and toys when there are older children in the household. Parents, children, their carers, and health care professionals all need to be targeted.

\section{Conclusion}

Almost all the asphyxiation deaths reported here could have been prevented by education, supervision, or structural modification of equipment. Preventable strategies need to include obligatory manufacturing standards, product labelling and warnings, and specific and targeted education of parents, child carers, and health care professionals. Special attention must be given firstly to ensuring a safe environment for infants, with respect in particular to bedding and food, and secondly to warnings and education about the dangers associated with ropes, in particular rope swings.

The authors wish to acknowledge the invaluable help of the Consultative Council on Obstetric and Paediatric Mortality and Morbidity and its staff, in particular Dr Bill Kitchen, and also Morbitity and its stafi, in particular Dr Bill Kitchen, and also principal registrar Mr David Stephens.

1 Consultative Council on Obstetric and Paediatric Mortality and Morbidity. Annual report on obstetric and paediatric and Morbidity. Annual report on obstetric and paediatric Council on Obstetric and Paediatric Mortality and Mobidity, 1992 .

2 Harrison J, Cripps R. Injury mortality, Australia 1992. Australian injury prevention bulletin. Adelaide: Nationa Injury Surveillance Unit. Issue 6, April 1994.

3 Waller AE, Baker SP, Szocka A. Childhood injury deaths national analysis and geographic variations. Am $\mathcal{f}$ Public Health 1989; 79: 310-5.

4 Kraus JF. Effectiveness of measures to prevent unintentional deaths of infants and children from suffocation and strangulation. Public Health Rep 1985; 100: 231-40.

5 Corey TS, McCloud LC, Nichols GR, Buchino JJ. Infant deaths due to unintentional injury, an 11-year autopsy review. Am $\mathcal{F}$ Dis Child 1992; 146: 968-71.

6 Bergeson PS, Hernried LS, Sonntag PL. Infant strangulation. Pediatrics 1977; 59 (suppl): 1043-6.

7 Baker SP, Fisher RS. Childhood asphyxiation by choking or suffocation. FAMA 1980; 244: 1343-6.

8 Feldman KW, Simms RJ. Strangulation in childhood: epidemiology and clinical course. Pediatrics 1980; 65: 1079-85.

9 Gilbert-Barness E, Hegstrand L, Chandra S, et al. Hazards of mattresses, beds and bedding in deaths of infants. $\mathrm{Am} \mathcal{Y}$ Forensic Med Pathol 1991; 12: 27-32.

10 Sturner WQ, Spruill FG, Smith RA, Lene WJ. Accidenta asphyxial deaths involving infants and young children. Forensic Sci 1976; 21: 483-7.

11 Cooke CT, Cadden GA, Hilton JMN. Hanging deaths in children. Am F Forensic Med Pathol 1989; 10: 98-104.

12 Hord JD, Anglin D. Accidental strangulation of a toddler involving a wall light switch. Am $\mathcal{F}$ Dis Child 1993; 147: $1038-9$.

13 Shepard RT. Accidental self-strangulation in a young child: a case report and review. Med Sci Law 1990; 30: 119-23.

14 Byard RW. Unexpected death due to acute airway obstruction in daycare centers. Pediatrics 1994; 94: 113-4.

15 Mittleman RE. Fatal choking in infants and children. $A m \mathcal{F}$ Forensic Med Pathol 1984; 5: 201-10.

16 Stallings Harris C, Baker SP, Smith GA, Harris RM Childhood asphyxiation by food. A national analysis and overview. $\mathcal{F} A M A$ 1984; 251: 2231-5.

17 Adams R. Protecting consumers: unsafe products maim and kill. Fournal of State Government 1989; 62: 104-6.

18 Office of Fair Trading. Consumer affairs (product safety) (children's toys) regulations, 1987. Victoria: Office of Fair Trading, 1987.

19 Nelson T. Hazard analysis of injuries relation to cribs. Washington: United States Consumer Product Safety Commission Bureau of Epidemiology, 1975: 12-25, Comm.

20 US Consumer Product Safety Commission. Federal code of regulations: commercial practices. Bulletin 16, part 1000 to end. Washington, DC: US Government Printing Office, 1978; 284-91.

21 Swedish National Food Administration. The National Food Administration's ordinance on food for infants and young children. (SLV FS 1978:17, 15.) Uppsala, Sweden: Food Standards Division, 1978. 